\title{
Social Skills Training for Autistic Children: A Comparison Study Between Inclusion and Mainstreaming Education
}

\author{
Guadalupe F. López* \\ California Lutheran University, USA
}

Submission: December 11, 2015; Published: July 29, 2016

*Corresponding author: Guadalupe F. Lópe; California Lutheran University, USA, Tel: 8057019894; Email: dr.gkirklin@gmail.com

\begin{abstract}
The educational institution is an ever evolving entity. With the passage of P.L.94-142 [Education for All Handicapped Children Act] in 1975, the educational system was faced with the challenge of including all students with disabilities into the general education setting. Yet, millions of students continue their education in separate settings or in isolated facilities within districts [mainstreaming education].

Significant amounts of research indicate that separate special education programs have not had the positive impact originally anticipated for students. Research also indicates that isolated programs have not prepared students adequately for their futures.

Abbreviations: IDEA: Individuals with Disabilities Act; LRE: Least Restrictive Environment; VCSSO: Ventura County Superintendent of Schools Office; CARS: Childhood Autism Rating Scale; IEP: Individualized Education Plan; SEEC: Social-Emotional Early Childhood; WMS: WalkerMcConnell Scale; UCSB: University of California; Santa Barbara; UCLA: University of California, Los Angeles
\end{abstract}

\section{Chapter 1}

\section{Introduction}

The individuals with Disabilities Act [IDEA] and the Least Restrictive Environment [LRE] requirements have been upholding in a series of federal district court decisions. These court decisions affirm the right of placement for students in the general education setting when educational benefits for the student are apparent [1].

The first premise of IDEA focuses on the right for all children to benefit from a free appropriate public education with appropriate supports and services, regardless of any disability. A second key premise is that all children have a right to a continuum of services and placements to meet their individual needs [2] The practice of educating children with and without disabilities in heterogeneous classrooms is referred to as inclusive schooling or commonly referred to as inclusion.

Inclusion is far more than the physical placement of a student with special needs in a general classroom. Inclusion involves a philosophy in which a school system allows for a variety of placements that offer the conditions under which every individual feels safe, accepted, and valued and is helped to develop his or her affective and intellectual capacities.

According to [1] there are some central differences between Full Inclusion Education and Mainstreaming Education: a. Inclusion allows students to receive education with their peers in the general education setting. General education

placement is the first alternative. With mainstreaming, students qualifying for service are placed into a resource room program as the first alternative.

b. In inclusionary settings, resource services are provided to the student in the classroom, even when the students' goals are different from their peers. With mainstreaming, students are removed from the classroom environment for supplemental educational services. As students reach their goals, they return to the classroom setting, usually without assistance or additional support. If the goals are not achieved, the student remains in a segregated program until goals are met.

c. In inclusionary settings, the student is removed from the classroom setting only after modifications, strategies, support and adaptations have not been successful in the classroom environment. A continuum of educational placements, ranging from the classroom to a segregated setting is offered, but the student moves to a segregated alternative only when such a move is necessary. With mainstreaming, however, the student is not given the opportunity to work through a continuum of services. The student is not provided the opportunity for 
success in the classroom environment with appropriate modifications, adaptations to the curriculum, and assistance.

\section{Inclusive Education for Elementary Students with Autism}

Research has documented that non-handicapped peers can be effective in teaching social skills for students with autism. The most efficient methods for addressing the students with autism in inclusive settings include appropriately structured play activities. This efficacy is based upon peers' training, and when the teachers actively prompt and then reinforce the interactions between the student with autism and the peers [3-5]. Consequently, there is currently a strong educational movement to integrate students with autism and other disabilities with their general education peers [6].

Moreover, research suggests that successful integration depends on the careful planning, development, and implementation of programs that emphasize both the academic and the social needs for students with Autism [6-9].

\section{Social Skills Training}

According to [8] social skills training have been a widely used intervention with children and adolescents. Social Skills Training is a process to remediate social skills deficits in children with emotional and behavioral disorders in order for them to attain social competence. The interest in social skills training with children is the relationship between early peer rejection and negative social adjustment. Social skills training programs are designed to teach pro-social skills. Appropriate social skills allow an individual to achieve three goals: [a] development of positive interpersonal relationships, [b] ability to cope with expectations of various social situations, and [c] execution of effective communication in social situations [8]. Contends that most contemporary approaches have been divided into four approaches: [a] the social skills approach, [b] the social problemsolving approach, [c] the social perspective taking, and [d] the selfcontrol training. Social skills in autistic children have always been a unique challenge. The question is whether social skills training in inclusive education programs are beneficial in improving social relationships and decreasing problematic behaviors.

\section{The Purpose of the Study}

Children with disabilities lose many opportunities for pleasurable experiences and friendships because of the misconceptions adults and the children's peers have about them. Philosophies on how to teach children with special needs have changed since Public Law 94-142 was passed. The philosophies have ranged from completely segregated schools and classrooms, to partial participation, to partial mainstreaming, to peer tutor programs, to reverse mainstreaming, or to full or partial inclusion. Often, the only difference between philosophies is found in the definition of the different programs.

According to [10] she believes that it is clear that the children with disabilities are the ones who are often the forgotten factor when philosophies clash. Too many children have lost or are loosing the opportunities of meeting their typically developing classmates while the debate ranges around them. Research shows that exposure to typical peers enhances social development; allows for opportunities to model positive role models in the classroom, the playground and in the community; elevates selfesteem; and educates typically developed children about their disabled classmates. With training, negative behaviors decrease in the presence of positive behaviors and increase, or stay the same, without support or training for the child with the disability or regular education classmate. Children with disabilities should be placed in settings where the positive behaviors can be modeled and training can occur. This is in the regular education setting with full inclusion programs.

The likelihood of failure is greater when the child with the disability is placed within the regular education setting with no backup support, no specialized training of the teachers, and no education of his or her typical classmates. Children in regular education classes tend to be overly critical. They often have negative feelings and offer no opportunities for friendship to the disabled child if they do not understand the reason for the behaviors. Such children with disabilities, such as autism often appear to be physically and intellectually at age-level, but can have bizarre and surprising behaviors resulting from their disability that can alienate other children [8] Research shows that when regular education children receive information about the disabilities, are given the chance to act as "peer tutors" or "buddies", and have full support of their teacher in times of confusion and frustration, the acceptance of the child with the disability increases dramatically [11].

The full inclusion program offers the regular education student the opportunity to learn about children with disabilities, specifically, children with autism. Teachers and staff receive training, information and hands-on demonstrations to aid in their inclusion program. The students in the regular education settings also receive information about the strengths and weakness in all people. The goal in offering information to the children is to build future peer tutor programs; offer friendship clubs; enhance the knowledge of the children and staff about disabilities; and to improve the lives of children who have traditionally had little or no opportunity for social involvement [10]. Consequently, social skills in autistic children in full inclusion programs can dramatically improve over children in mainstreaming programs.

The purpose of the study is to compare the effectiveness between inclusion and mainstreaming education in obtaining better outcomes in social skills for autistic children ages 3-8 years. Autistic children and their families deserve to be given the most beneficial treatment because of the far reaching detrimental effects of their condition. Continued field research on the effectiveness of inclusion education to obtain better outcomes in social skills for autistic children will provide essential information to clinicians, educators, social workers and researchers. 


\section{Chapter 2}

\section{Literature Review}

The literature on the following topics is reviewed in this chapter: Changes in the Population of Persons with Autism and Pervasive Developmental Disorders in California's Developmental Services System, Definition of Autism, Social skills training, Inclusion and Mainstreaming Education, Benefits of Inclusion Education for Children with developmental disabilities, and Treatment for Autistic Children.

\section{California's Developmental Services System \\ Findings}

From December 1998 to December2002, the population of persons with autism in California's Developmental Services System nearly doubled. For the four-year-period from December, 1998 to December, 2002, there was a net increase of 10,017 individuals [a 97\% increase] in the autism caseload. At the end of December 1998, there were 10,360 persons with autism Codes 1 and 2 served by all 21 regional centers, and by the end of December 2002, the total was 20,377. Additionally, comparing the figures from December 1987 to December 2002, there was a $634 \%$ increase in autism [Codes1 and 2] in the 15 years from 1987 to 2002 .

\section{Age Distribution}

Interestingly, this report shows a shift toward younger persons with autism [Codes 1 and 2] between 1987 and 2002. In 1987 , the autism population served by regional centers totaled 2,778 persons. The highest percentage of persons in 1987 was in the 20 to 24 year age-range. By the end of 2002, when the autism population totaled 20,377 persons, the greatest number of persons $[4,282]$ shifted to children in the 5 to 9 year age-range. By 2002, 70\% of all persons with autism in the regional center system were under 15 years of age, compared to 35\% in 1987.

\section{Ethnicity}

This report also shows shifts among ethnic groups in the number and percentages of persons with autism between 1987 and 2002. Relative to the entire population of persons with autism, Asians and Hispanics increased the most in the 15-year interval between 1987 and 2002. Relative to the entire autism population in 2002, the Asian and Hispanic proportion more than doubled compared to 1987.

\section{Gender}

In the 15-year comparison, the report shows a $5 \%$ proportional increase in males with autism compared to females. In [12] 2,140 individuals with autism were male [77.03\%] and 638 individuals were female [22.97\%]. By the end of December 2002, 16,675 individuals with autism were males [81.83\%] and 3,702 were females [18.17\%].

The Department's 1999 Report on Changes in the Population of Persons with Autism and Pervasive Developmental Services System reached two general conclusions: [a] the number of persons with autism continues to increase dramatically, and [b] autism is and will almost probably continue to be the fastest growing disability served by the regional center system [California Department of Developmental Services, 2003].

\section{Definition of Autism}

Autism is a developmental disorder that is behaviorally defined [10]. Autism is defined in the DSM-IV [2000] as a "pervasive developmental disorder", and it is one of the five subcategories of Pervasive Developmental Disorders. Autism is a disorder that manifests itself in infancy, severely affects the development of social interaction, communication skills, and behavior. It results in the presence of stereotyped behaviors, interests and activities. Typically apparent before age three, autism affects four times as many boys as girls and is found in families of all races, religious and social classes.

Autism is one of the most prevalent developmental disorders, affecting 1 in 1000 births to 2 in 1000 births if the full spectrum of autistic behavior is included - autism, Pervasive Developmental Disorder Not Otherwise Specified [PDD NOS], Asperser's Disorder, Rhett's Disorder, and Childhood Disintegrative Disorder [10]. Manifestations of the disorder vary greatly depending on the developmental level and chronological age of the individual. Autistic Disorder is sometimes referred to as early infantile autism, childhood autism, or Kenner's autism [DSM-IV-TR] [1113]. Autism is also viewed as an expression of an identified neurological disorder.

The exact cause or causes of autism are currently unknown; although recent research shows a spectrum of impairments at both the anatomical and microscopic levels. There is no specific clinical answer to the definition of autism since every case is unique. It is important to consider the degree of heterogeneity possible among people with autism. Individuals with autism will vary in the number of symptoms they present, the severity of those symptoms, the degree of cognitive impairment they will experience, and the number and type of associated medical problems they will have. The individual's involvement in appropriate treatment and education also needs to be considered; although the majority of individuals with autism will require life-long support services, research is indicating that early, behaviorally based intervention and placement in highly structured, family-focused and community-based services is critical to obtain the best possible outcome $[14,15]$. And it is also important to consider that autism is a disorder of development and, as such, will affect the individual in different ways during different stages of development [16].

According to [16], the autistic disturbance is generally considered to include some combination of the following symptoms.

a. Autistic children exhibit a profound failure to relate to other people, which is often apparent from birth. They may show an absent or delayed social smile, and may not reach upwards in anticipation of being picked up. Some children fail to form emotional attachments to significant people in 
their environment, for example, not showing distress when the mother leaves the room. Similarly, a child may play in the vicinity of other children without interacting or participating with them.

b. Autistic children commonly show various levels of impaired or delayed language acquisition and comprehension. Many autistic children are mute and others may show echolalia. Immature grammar, pronoun reversals, and/or inability to use abstract terms may also be apparent.

c. Many children show apparent sensory dysfunction, as if they do not see or hear some environmental events. They may exhibit under -or over responsiveness to touch, light, sounds, or pain. For instance, the child may not exhibit a startle response to a loud disturbance, but may respond to the sound of a candy wrapper, or may tantrum excessively every time a siren goes by.

d. Many autistic children show inappropriate and/or flat affect. They may not display appropriate facial expressions and may not exhibit fear in dangerous situations, such as crossing the street. They may respond to even simple requests with severe, prolonged tantrums. They may also laugh and giggle uncontrollably in the absence of apparent eliciting stimuli, or cry uncontrollably for hours.

e. Typically, autistic children will occupy themselves for hours with stereotyped, repetitive self-stimulatory behaviors, which serve no apparent purpose other than providing the child with sensory input. Commonly, self-stimulatory behaviors take the form of manipulation of hands or fingers in front of her eyes, eye crossing, repetitive, meaningless vocalizations [e.g. "aeh, aeh, aeh..."] suspending or spinning objects in front of the eyes, mounting objects, hand tapping, body rocking, and other stereotyped behavior. Such behaviors have been found to significantly impair learning in autistic children [17].

f. Autistic children often fail to develop normal, appropriate play. They may forsake toys altogether, preferring instead to spin a lampshade or flick a light switch on and off. Social play with peers may develop spontaneously, but usually does not.

g. Autistic children commonly show obsessive, ritualistic behaviors which have been characterized as a profound

resistance to change in the environment or normal routines. Familiar bedtime routines, insistence on one type of food, one type of furniture arrangement, and particular routes to familiar places are examples of routines which, when altered even a minor fashion, can create extreme disruption in a child's behavior. Table 1 summarizes some if the characteristics presented and associated with autism.

Table 1: Characteristics Presented and Associated with Autism.

\begin{tabular}{|c|c|}
\hline Domain & Description \\
\hline $\begin{array}{l}\text { Development } \\
\text { Age of Onset }\end{array}$ & $\begin{array}{l}\text { Deficits usually noted by three years of age. } \\
\text { Delay in onset of first words and first phrases. Uneven skill development. } 60 \% \text { have IQ's under 50; } \\
20 \% \text { have IQ's between 50-70; } 20 \% \text { have no mental retardation, with some individuals in the gifted } \\
\text { range (these figures are only approximate). }\end{array}$ \\
\hline Social & $\begin{array}{l}\text { Impairments in understanding social gestures, eye contact, social smile (reciprocal), showing and } \\
\text { directing, sharing/turn-taking, offering or seeking comfort, appropriate use of facial expression, } \\
\text { consistency of social responses. } \\
\text { Imaginative play, ability to play social games, ability to make friends, ability to judge social situations, } \\
\text { imitative social play, response to other children, ability to "read" another's non-verbal cues. }\end{array}$ \\
\hline Communicative Domain & $\begin{array}{l}\text { Impairments in complexity of non-echoed utterances, functional language (often echolalia), social } \\
\text { "chat", reciprocal conversation, appropriateness of language such as grammar/pronominal confusion, } \\
\text { use of neologisms and Idiosyncratic language, demonstration of verbal rituals, imitation of language, } \\
\text { pointing to express interest, instrumental gestures, attention to voice modulation, comprehension of } \\
\text { simple language, direct gaze, reciprocal gaze, } 40-45 \% \text { of students with autism are non-verbal. }\end{array}$ \\
\hline Behavioral Characteristics & $\begin{array}{l}\text { Individuals with autism can have circumscribed interests, unusual preoccupations, repetitive use of } \\
\text { objects, compulsions/rituals, unusual sensory interests, hand/finger mannerisms, other complex } \\
\text { mannerisms, such as self-stimulatory behavior, self-injury, and special skills. }\end{array}$ \\
\hline Miscellaneous Characteristics & $\begin{array}{l}1 / 4 \text { to } 1 / 3 \text { have epilepsy. } \\
4 \text { out of } 5 \text { will be boys. } \\
\text { Girls usually have more severe characteristics. } \\
\text { Same incident rate in all countries, races, socio-economic status. } \\
\text { Some individuals have poor motor skills. } \\
\text { Some individuals have sensory issues. }\end{array}$ \\
\hline
\end{tabular}

\section{Neurological Disorders}

By tradition, autism has only been diagnosed without the evidence of known neurological dysfunction. However, the prevalence of evidence now strongly suggests that autism may involve a neurological disorder [18-20]. In addition, recent evidence suggests that some impairment of auditory processing in 
the language-dominant hemisphere of autistic children may exist $[21,22]$ suggest that the symptoms of autism could express some physical dysfunction within the central nervous system which remains to be characterized. Whatever the exact cause is, however, neurological improvement does appear possible with behavioral intervention [21]. Note. Some statistics are subject to debate and need further research.

Individuals with autism differ extensively from one another. Although they may exhibit different characteristics among those outlined above, all individuals with autism have underlying similarities of impairment in communication, socialization, interests, and behaviors. Severity of autism can range from very mild to quite severely impair. This can be confusing to many parents and professionals trying to understand the disorder of autism. However, parents and professionals need to remember that all individuals with autism can progress and learn when their programming is designed around their unique, specific needs [10].

\section{Social Skills}

One definition of appropriate social skills is that they are prescribed ways of behaving; they are expectations of particular groups as to how group members will conduct themselves in private and in public. Prescriptions for what is socially appropriate vary from community to community and society to society. Variations exist even within the tight circle of home, preschool, and neighborhood. But confusing choices often result, especially for young children. However, rather than attempting to define a term like social skills, the following list is considered according to [23]. The major social skills to be learned during the early years relate to getting along with others.

i. Interacting with children and adults, in a variety of ways, at home and away from home.

ii. Trusting and enjoying known adults outside the immediate family.

iii. Recognizing and protesting inappropriate advances from known or unknown adults within or outside the family.

iv. Attending to self-care needs at home and in public places with consideration of others.

v. Sometimes initiating play ideas with children, other times, following children's lead.

vi. Participating in group activities through listening, taking turns, and contributing to group effort.

vii. Sometimes putting aside individual needs and interests so the needs and interests of the group may be met.

viii. Working and playing independently as well as operatively; learning to be alone without feeling isolated or rejected.

ix. Using language as the powerful social tool it is for persuading, defending, reasoning, explaining, solving problems, and getting needs and preferences attended to.

Children with developmental disabilities, such as autism, like all young children, need to learn to get along with others. To do this, they must learn appropriate social skills. Such learning may be more difficult for children with developmental problems. Like all other skills, social skills are dependent on every other area of development. Notwithstanding, children of all developmental levels can master basic social skills as prescribed by their respective families, schools, and communities [23].

\section{Inclusion and Mainstreaming Education}

Inclusion differs from mainstreaming in that mainstreaming provides disabled students the opportunity to be placed in regular class- with other disabled peers, based on the student ability to keep up with work assigned, with some modifications. Instructional support and related services are typically provided outside the regular education setting. Integration, a term popularized in the 1980s, was used to indicate the placement of a disabled child in a special class, in a typical school, where the student could participate in some activities with non-disabled peers. Special education services were usually provided in a special education class. This fragmented approach caused children to become lost in the system [24].

Inclusion refocuses the LRE [Least Restrictive Environment] provision to keep a student in the class that he or she would attend if not disabled. Services are provided in the regular classroom unless the nature and severity of the student's individual educational needs are such that a more restrictive setting must be considered for the child to be provided an appropriate education. An educational debate is ongoing regarding inclusive education of disabled children. This conflict involves two basic groups: [1] parents, teachers, and administrators who support inclusion; and (2) representatives of these groups who are against inclusion as an educational philosophy and practice [25].

Inclusion means that children with special needs attend preschool, childcare, and recreational programs with their typically developed peers. However, inclusion is not about a place, or an instructional strategy, or a curriculum; inclusion is about belonging, being valued, and having choices. Inclusion is about accepting and valuing human diversity, and providing the necessary support so that all children and their families can participate in programs of their choice. "Inclusion is a right, not a privilege for a select few" [Roberti V. Board of Education in Clementon School District, 1993]. The call for inclusion is coming from families, professional organizations, and advocacy groups [26].

\section{Benefits of Inclusion Education \\ Benefits to Children with Autism}

Children with autism have pronounced impairments in social and communication development that hinder their interactions with peers and family members. When a child with autism does not have access to adaptive role models, progress toward improving social and communications skills is often hampered. Regular education can offer valuable opportunities for social interactions with peers. However, placement in regular education alone does 
not ensure success [10]. Children with autism require supports to help them develop and generalize necessary social skills. With adequate supports in place, significant improvements in social interactions can occur [10]. Thus, inclusion education offers a door for better outcomes in social skills for children with autism.

\section{Benefits to Children to Typical Children}

Typical peers also benefit from participation in an inclusion program by developing a heightened awareness of the needs of children with disabilities. This can lead to greater sensitivity toward others and acceptances of the relative strengths and weakness that people have. Many parents acknowledge these benefits of inclusive programs [24].

\section{Benefits of peer tutoring/social skills programming}

Teachers have long recognized the additional benefits that peer influence has on teaching academics and on the student's self-esteem. Implementing formal peer tutor programs with a strong foundation of social skills, the students with disabilities benefit. Students who experience difficulty with peer interactions or reciprocal conversations are presented with numerous opportunities in which peers frequently and repeatedly request appropriate responses from them. This provides the students with the best environment to develop skills in both the social and language domains under the guidance of a teacher.

With consistent and frequent exposure to peer programs, teachers and parents report that students gain increased language production, decreased solitary play, and increased appropriate social skills. Teachers and parents have begun to recognize that it is extremely difficult for adults to teach age-appropriate social skills to a child. However, children often readily learn these skills from another child, making peer tutor programs and social skills training important, especially during the school years [10]. These programs are well worth investigating for any professional interested in social and language difficulties in autism.

\section{Treatment for Autistic Children}

Several studies reveal that involving peers in social skills interventions provides children with autism the opportunity to observe, imitate and learn from the social behaviors of their typically developing peers [27]. However, to increase the social awareness of these children in the inclusive setting, educators must carefully design peer interventions to take into account the range of special characteristics found in children with autism. The purpose of this topic is to review two recent articles that focus on teaching peer social skills to children with autism and to note some practical implications of this research for professionals interested in social skills training in autism.

According to one of the first investigations in the autism social skill literature performed by Free [28], it was utilized naturalistic behavioral observation to clarify the social behavior of children with autism and their typically developing peers, and to compare each group's behavior in the same setting. Participants were five children, four male and one female, all with the diagnosis of Autism Spectrum Disorder who were enrolled in inclusive classroom settings. Once or twice per week, examiners observed and recorded three target behaviors for each group: [a] the number of minutes appropriately engaged in a task, [b]the number of stimulus items used while task-engaged and [c] the number of social-communicative interactions emitted.

\section{Results}

Indicated that children with autism used the same number of task objects as comparison children; however, the children with autism spent far less time engaged with each item. Overall, children with autism were engaged in tasks only one-half as long as contrast children. Additionally, the children with autism rarely engaged in social-communicative interactions with other children, whereas comparison children did. However, the amount of social interaction between autistic and comparison children was found to be similar to previous reports regarding their rates of communication with adults.

Consistent with the extant autism literature, these results provide strong naturalistic evidence that children with autism have severe deficits in the area of peer interaction skills. It is hypothesized that children with autism may become more willing to interact with others if they are given an opportunity to practice newly acquired social skills with normally developing classmates also placed in the skills training program. Since inclusion is the ultimate goal of special education, results of this study suggest systematic and long-term social skills training should be considered an integral part of inclusion programs for children with autism.

In other study performed by Kemps et al. [18] it was examined the contributions peers can make to the generalization of social behaviors for children with autism through peer social skills programs.

Two investigations were completed, and each examined the role of peers when trained in explicit interaction strategies with children with autism during and after specific treatment. Generalization of these skills for target and peer participants was a particular focus of study. Participants for study 1, which examined the effects of generalization on social skills, cooperative learning and peer training, were 5 students with autism and 51 general education peers. Three peer groups were derived for the analysis of generalization:

a. Those who participated in cooperative learning groups with children with autism,

b. Those in social skills groups with children with autism, and

c. A group of peers familiar with the students with autism but who did not receive training. Results indicated that during cooperative learning groups with peers, time engaged in interaction increased from 30 to 191 seconds, a rate similar 
to what was found for typically developing peers. However, during social skills training groups, students with autism increased their peer interaction time from a range of 7-56 to 152-262 seconds.

Study 2 included 34 students with autism and approximately 130 peers who participated during the initial year and 120 more during the final probe year. Students received a variety of peer mediation programs:
A. Social skills groups,
B. Lunch buddy groups,
C. Recess buddy groups and
D. Tutoring programs. Peers and target students received direct instruction in the use of skills within the context of each activity.

Results indicated that for students with autism improvements were made in social interaction skills with non-disabled peers. Average interaction duration time between students with autism and trained peers [393 sec] was longer than with familiar peers [301 sec], which was longer than the time spent interacting with stranger peers [246 sec].

These findings are particularly important for school psychologists because they suggest the practicality of peer mediation programs to support elementary classrooms for children with autism. Second, these results indicate that social skills programs alone are not as efficient as a program that includes both academic and social mediation, and that including trained peers in these cooperative learning programs is essential for increased social interactions for students with autism placed in general education. Statement of the Problem. The problem is to examine whether inclusion education for autistic children is more effective than mainstreaming education. The children in this study will be 3-to 8-year-olds diagnosed with Autism. The children will be enrolled in inclusion programs and mainstreaming education for the past 12 months of school calendar year.

\section{The specific objectives of the study area)}

To obtain the degree of change in social skills in children participating in the scoring of social skills through testing.

b) To identify the degree of change in social skills in children participating in the scoring of social skills with the initial evaluation of the school and the results of the testing.

c) To compare the effects of the inclusive and mainstreaming education in their social skills.

d) To compare the changes in the population of persons with autism and pervasive developmental disorders in California's Developmental Services System from 1987 through 2002.

e) To compare the financial effects of social training education and the treatment of autistic individuals who did not receive social skills education or inclusion education during childhood — untreated autistic expenses.

\section{Research Questions}

The research questions of this study were as follows:

a. Will autistic children in inclusion programs have higher levels of social skills than mainstreaming children?

b. Is there a relationship between improvement of social skills and inclusion education?

c. Will inclusion programs provide a financial reduction in educating autistic children compared to the treatment of autistic individual who did not receive social skills education or inclusion education during childhood?

\section{Chapter 3}

\section{Method}

\section{Participants}

The first delimitation of the study is the profile of the participants. A total of 160 participants will serve as the base sample. Subjects will be enrolled for scoring if they meet three criteria: [a] only 3-to 8-year-old students; [b] participants will be currently enrolled for the last 12-months school calendar year within the Ventura County Superintendent of Schools Office [VCSSO] and the Ventura County Superintendent of Schools Special Education in the areas of Oxnard, Camarillo, Fillmore, Santa Paula and Ventura California; [c] the participants will be enrolled for the last school calendar year within the VCSSO in Pleasant Valley School District, Rio School District, Fillmore Unified School District, Briggs Elementary School District and Ventura Unified School District, Oxnard Elementary School District, and Santa Paula Elementary School District; [d]the participants will be enrolled for the last 12- months within the Ventura County Superintendent of Schools Special Education in San Miguel Preschool in Oxnard, Santa Rosa School in Camarillo, Phoenix School in Camarillo, Douglas Penfield School in Ventura, Dire School in Oxnard, Hollywood Beach in Oxnard, Valle Linda in Camarillo, and Phoenix - Los Nogales in Camarillo.

\section{Measures}

The clinical diagnosis of autism will emphasize emotional detachment, interpersonal isolation, impairments in communication and social skills, little toy or peer play, rituals, emotional vulnerability, and onset in infancy. The diagnosis of autism will be made prior to family contact with the project. Participants will be assessed in their development of their social skills by the initial Individualized Education Plan [IEP], the Child Autism Rating Scale [CARS], the Vineland Social-Emotional Early Childhood Scales, and the Walker-McConnell Scale of Social Competence and School Adjustment for the screening and identification of social skills.

The Individualized Education Plan[IEP]: Includes information relevant to the student's performance in the areas of cognitive ability, academic performance, communication skills, motor skills, sensory, health, social and emotional, adaptive 
functioning skills, and vocational assessment. Psychological and related reports may also be included. These IEPs are written annually and are updated throughout the year. These documents are a part of the student's permanent file. Some special education departments encourage paraprofessionals to read the IEP file [11].

The Childhood Autism Rating Scale [CARS] [Scholar et al., 1988]: is an individually administered instrument that consists of 15 behaviorally rated items designed for the identification and assessment of autistic children. The CARS is an observational instrument that can be used to reliably distinguish children ages 2 and over with the autistic syndrome from children with other developmental disorders, as well as to differentiate among levels of severity within the autistic syndrome.

The CARS was also designed to replace subjective clinical judgments with objective criteria based on empirical research. It can be used during observations of child behavior in a variety of settings, or may be used with information gathered from chart or record reviews. The CARS is composed of 15 4-point scales on which a child's behavior is rated on a continuum from within normal limits [1] to severely abnormal [4] for chronological age. Total scores are used to categorize a child on a continuum ranging from non-autistic, to mild to moderate autism, to severe autism. The CARS is supposed to be an initial aid in the classification process. The scores are as follows: 16 rating scores: Relating to People, Imitation, Emotional Response, Body Use, Object Use, Adaptation to Change, Visual Response, Listening Response, Taste-Smell-Touch Response and Use, Fear or Nervousness, Verbal Communication, Nonverbal Communication, Activity Level, Level and Consistency of Intellectual Response, General Impressions, Total.

Internal consistency [coefficient alpha] is found to be .94 . Interpreter reliability is .71 , with a range of .55 [Level and Consistency of Intellectual Response] to .93 [Relating to People]. Test-retest reliability of CARS scores for 91 cases assessed 1 year apart resulted in a correlation of .88. Test-retest reliability of CARS diagnoses [i.e., non-autistic, mild-moderate autism, or severe autism] from the second to third annual evaluation resulted in a coefficient kappa of .64. The CARS has a correlation of .84 . Validity of the CARS across different settings reveals a coefficient Kappa's of .75 [parent interview vs. psycho educational testing], .86 [classroom observation vs. psycho educational testing], and .63 [case history review vs. psycho educational testing].

The Vineland Social-Emotional Early Childhood Scales [Sparrow et al., 1998] is an instrument designed to assess the social and emotional functioning of children from birth through 5 years 11 months of age. The Vineland SEEC Scales are a subset of items from the Socialization Domain of the Vineland Adaptive Behavior Scales, Expanded Form. The Vineland SEEC is designed to be individually administered through a semi structured interview with a respondent who is familiar with the child's behavior. The test consists of three scales: Interpersonal Relationships, Play and Leisure Time, and Coping Skills that combine to yield a SocialEmotional Composite score.
Information on the reliability of the Vineland SEEC Scales is also presented in a clear and comprehensive manner. Internal consistency levels are adequate, with median values of the Interpersonal Relationships, Play and Leisure Time, and Coping Skills Scales ranging from 80 to 87 . The internal reliability coefficients of the Scale Composite, across six age groups, range from 89 to 97 with a median value of 93 . Adequate stability is also well documented with the vast majority of the component scale and composite score test-retest correlations falling between 71 and 79.

The Walker-McConnell Scale of Social Competence and School Adjustment [WMS; Walker \& McConnell, 1988] was designed primarily for use in the screening and identification of social skills deficits among elementary aged children in school. The WMS is quickly administered and scored, and focuses on important domains of child functioning. Refreshingly divergent from most other rating scales of child behavior, the WMS is positively focused [i.e., it centers on skills rather than problems in both the item wording and the resulting scales].

The inter scale correlations reported for the national norm sample of $.67, .74$, and .67 are too large to support the case for separate subscales. The interpreter reliabilities reported are low to moderate, ranging from .11 to 74 [median $=.49$ ] for the subscales . Interpreter reliabilities for the total score are .53 and .62 for two samples of 13 and 17 severely disturbed children of elementary and middle school age, and .63 to .83 for a sample of 19 Head Start children ages 4 and 5 years. Test-retest reliabilities are moderate to high, ranging from .90 to 97 for a 2-week interval, and from .61 to .70 for a 6 -month interval. High coefficient alphas are reported that exceed .90 for all grade levels for all scales, including the total score. No evidence of individual item reliability is reported.

\section{Procedure}

The data will be collected by means of an in-depth, semi structured interview and a brief demographic questionnaire of the student at the end of the interview. The interview protocol will be based on that of Koegel et al. [29] for the evaluation of the student's current social skills, and the recollection of data information from the Individualized Education Plan [IEP]. Additionally, the participants will be assessed with the Walker-McConnell Scale of Social Competence and School Adjustment for the screening and identification of social skills deficits; and the Vineland SocialEmotional Early Childhood Scales [Vineland SEEC Scales] for the assessment of the social and emotional functioning of children. The Child Autism Rating Scale [CARS] will be applied for the identification and assessment of autistic children. Participants will be diagnosed with autism by either of the following professionals and/or institutions: The Tri-Counties Regional Centers, University of California, Santa Barbara [UCSB], University of California, Los Angeles [UCLA], a family neurologist, a family psychiatrist, and/or a family physician [30].

A preliminary meeting with the school districts and the teachers will be held to discuss the participation of the students 
in the study, the content of the inclusion and mainstreaming education, and procedures for incorporating this activity into their courses. By mid-January of 2006, parents will be informed of the study and will be asked to provide consent to participate.

On the first chosen day, teachers will be given the semi structured interview and a brief demographic questionnaire of the student at the end of the interview. Subsequently, the IEP for every student will be analyzed. On the second day, upon arrival at the designated classroom, the student will be given The Child Autism Rating Scale [CARS] for the identification and assessment of the different levels of autism in the participant. The lead facilitator will instruct the student with the procedural questions according to the administration manual of the instrument [administration time depends on the participant]. After the lead facilitator read the instructions, the student will proceed with the activities of the instrument.

On the third day, the student will be given the WalkerMcConnell Scale of Social Competence and School Adjustment for the screening and identification of social skills deficits [510min]; and the Vineland Social-Emotional Early Childhood Scales [Vineland SEEC Scales] for the assessment of the social and emotional functioning of children [15-25min].

For the initial interview on overall social skills [will be 1-very little to 7-very much], means and standard deviations will be computed for each group [inclusion and mainstreaming].

Students will be divided into two groups: [a] inclusion and [b] mainstreaming. This study will examine the higher levels of social skills with the two programs, inclusion and mainstreaming. Because higher social skills indicate better outcomes in socialization, a high mean is desirable.

A Two-Way Analysis of Variance [2-Way ANOVA] between subjects will be conducted. This will be used to determine the significance of the main effects and the interaction at the .05 level. This study will show the interaction between the effectiveness of social skills in autistic children and the inclusion education. Three levels of autism are measured: [a] mild impact, [b] moderate impact, and [c] severe impact. Thus, by comparing the column means, we are answering the question of which program is more effective in general without regard to how the impact of autism is.

\section{Hypotheses}

The derivation of the hypothesis, the general research hypothesis and the specific hypothesis are presented in this section. This study will emphasize the recent trend toward inclusion in general education, there is an increased number of children with autism and other pervasive developmental disorders who are being educated in the same classroom settings as their normally developing peers. As a consequence, considerable attention has been dedicated to promoting effective intervention techniques to enhance peer social skills among children with autism. Teaching appropriate peer interactions is an integral element of a comprehensive behavioral program for children with autism
[Taylor, 2001]. As children with autism grow and acquire the basic skills necessary to function effectively in a one-on-one inclusive setting, the need for peer interaction skills becomes apparent.

\section{General Hypothesis}

Autistic Students who receive inclusion education approach in preschool and elementary school will have better outcomes in their social skills than those who receive mainstreaming education approach.

\section{Specific Research Hypothesis}

Autistic students, ages 3 to 8 who receive inclusion education approach in preschool and elementary school within the Ventura County Superintendent of Schools Office [VCSSO] will have better outcomes in their social skills than those who receive mainstreaming education within the Ventura County Superintendent of Schools Office [VCSSO] Special Education Department.

\section{References}

1. Hammeken PA (1996) Inclusion: An Essential Guide for the Paraprofessional. Minnetonka MN, USA.

2. Tilton L (1996) A Fresh Look. Practical Strategies to Help All Students Succeed. Shorewood MN, USA.

3. Strain PS, Shores RE, Timm MA (1977) Effects on Peers social initiations on the behavior of withdrawn preschool children. Journal of Applied Behavior Analysis 10(2): 188-198.

4. Odom SL, Hoyson M, Jamieson B, Strain PS (1985) Increasing handicapped preschoolers peer social interactions: Cross-setting and component analysis. Journal of Applied Behavior Analysis 18(1): 3-16.

5. Roeyers H (1996) The influence of non-handicapped peers on the social interactions of children with pervasive developmental disorder. Journal of Autism and Developmental Disorders 26(3): 303-320.

6. Kamps DM, Barbetta PM, Leonard BR, Delquadri J (1994) Class wide Peer tutoring: An integration strategy to improve reading skills and promote peer interactions among students with autism and general education peers. J Appl Behav Anal 27(1): 49-61.

7. Gaylord-Ross RJ (1989) Integration Strategies for Students with Handicaps. Baltimore: Brookes.

8. Gresham FM (1986) Strategies for enhancing the social outcomes of mainstreaming: A necessary ingredient for success. In: CJ Meisel (Ed), Mainstreaming handicapped children: Outcomes, Controversies, and New Directions.

9. Sailor W, Anderson JL, Halvorsen AT, Doering K, Filler J, et al. (1989) The Comprehensive Local School: Regular Education for All Students with Disabilities. Baltimore.

10. Wagner S (1999) Inclusive Programming for Elementary Students with Autism. Arlington TX, USA.

11. Garfinkle AN, Schwartz IS (2002) Peer imitation: Increasing social interactions in children with autism and other developmental disabilities in inclusive preschool classrooms. Topics in Early Childhood Special Education 22(1): 26-38.

12. Lovaas OI (1987) Behavioral treatment and normal educational and intellectual functioning in young autistic children. Journal of Consulting and Clinical Psychology 55(1): 3-9.

13. Laushey KM, Heflin LJ (2000) Enhancing social skills of kindergarten children with autism through the training of multiple peers as tutors. 
Journal of Autism and Developmental Disorders 30(3): 183-193.

14. Edwards DR, Bristol MM (1991) Autism: Early identification and management in family practice. American Family Physician 44(5): 17551764.

15. Lovaas OI (1987) Protection for clients undergoing aversive/restrictive interventions. Education and treatment of children 10(4): 311-325.

16. Holmes DL (1998) Autism through the lifespan: The Eden Model. Bethesda, MD: Woodbine House.

17. Koegel RL, Covert A (1972) The relationship of self-stimulation to learning in autistic children. Journal of Applied Behavior Analysis 5(4):381-387.

18. Blackstock E (1978) Cerebral asymmetry and the development of early infantile autism. Journal of Autism and Childhood Schizophrenia 8(3): 339-353.

19. Newsom CD, Rincover A (1979) Behavioral assessment of autistic children. In: EJ Mash \& LG Terdal (Eds.), Behavioral Assessment of Childhood Disorders.

20. Student M, Sohmer H (1978) Evidence from auditory nerve and brainstem evoked responses for an organic brain lesion in children with autistic traints. Journal of Autism and Childhood Schizophrenia 8: 13-20.

21. Koegel RL, Rincover A, Egel AL (1982) Educating and Understanding Autistic Children. San Diego, CA.

22. Ritvo ER, Freeman BJ (1978) National society for autistic children definition of the syndrome of autism. Journal of Autism and Childhood Schizophrenia 8(2): 162-167.
23. Allen KE (1992) The Exceptional Child: Mainstreaming in early childhood education. Albany, NY: Delmar Publishers. In: Baron-Cohen S \& Bolton P (Eds.), (1993) Autism: The Facts. Oxford University Press, NewYork, USA.

24. Dawson P (1987) Assistant secretary of education calls for more special education/regular education cooperation. Communiqué 15(6): $1-3$

25. Aefsky F (1995) Inclusion Confusion: A guide to educating students with exceptional needs.

26. Allen KE, Schwartz IS (1996) The Exceptional Child: Inclusion in early childhood education. Albany, NewYork, USA.

27. Kamps D, Royer J, Dugan E, Kravits T, Gonzalez-Lopez, et al. (2002) Peer training to facilitate social interaction for elementary students with autism and their peers. Exceptional Children 68(2): 173-187.

28. Koegel LK, Koegel RL, Frea WD, Fredeen RM (2001) Identifying early intervention targets for children with autism in inclusive school settings. Behavior Modification 25(5): 745-761.

29. Wetherby A, Koegel RL, Mendel M (1982) Central auditory nervous system dysfunction in echolalic autistic individuals. Journal of Speech and Hearing Research.

30. Hier D, LeMay M, Rosenberber P (1979) Autism and unfavorable leftright asymmetries of the brain. Journal o Autism and Developmental Disorders 9(2): 153-159. 